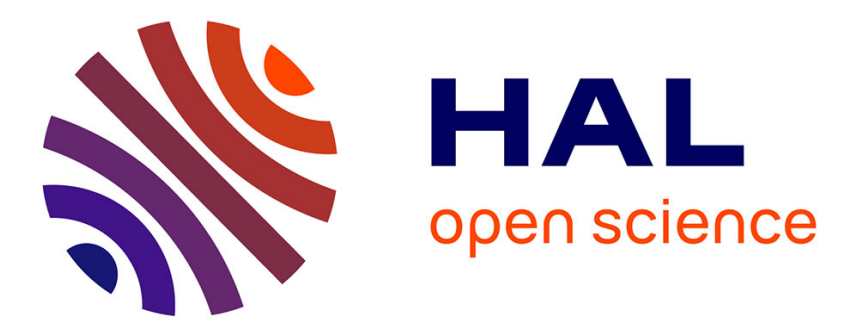

\title{
Automatic spawning detection in oysters: a fault detection approach
}

Hafiz Ahmed, Rosane Ushirobira, Denis Efimov, Damien Tran, Mohamedou Sow, Jean-Charles Massabuau

\section{- To cite this version:}

Hafiz Ahmed, Rosane Ushirobira, Denis Efimov, Damien Tran, Mohamedou Sow, et al.. Automatic spawning detection in oysters: a fault detection approach. Proc. ECC'15, Jul 2015, Linz, Austria. hal-01140324

\section{HAL Id: hal-01140324 \\ https://hal.inria.fr/hal-01140324}

Submitted on 8 Apr 2015

HAL is a multi-disciplinary open access archive for the deposit and dissemination of scientific research documents, whether they are published or not. The documents may come from teaching and research institutions in France or abroad, or from public or private research centers.
L'archive ouverte pluridisciplinaire $\mathbf{H A L}$, est destinée au dépôt et à la diffusion de documents scientifiques de niveau recherche, publiés ou non, émanant des établissements d'enseignement et de recherche français ou étrangers, des laboratoires publics ou privés. 


\title{
Automatic spawning detection in oysters: a fault detection approach
}

\author{
Hafiz Ahmed, Rosane Ushirobira, Denis Efimov, Damien Tran, Mohamedou Sow, Jean-Charles Massabuau
}

\begin{abstract}
Using measurements of valve activity in a population of bivalves under natural environmental condition (16 oysters in the Bay of Arcachon, France), an algorithm for the automatic detection of spawning period of oysters is proposed. The algorithm is based on the fault detection approach and it works through the estimation of velocity of valves movement activity, which can be obtained by calculating the time derivative of the valves distance. A summarized description on the method used for the derivative estimation is provided, followed by the associated signal processing and decision making algorithm to determine spawning from the velocity signal. A protection from false spawning detection is also considered by analyzing the synchronicity in spawning. Through this study, it is shown that spawning in a population of oysters living in their natural habitat (i.e. in the sea) can be automatically detected without any human expertise, like visual analysis.
\end{abstract}

Index Terms-Fault detection, signal processing, oysters, spawning detection

\section{INTRODUCTION}

Global awareness regarding our aquatic environment increases daily. This consciousness combined with the pressure from the general public, scientists and environmental protectionists and various other reasons lead to more and more strict rules and regulations for the protection of environment. In order to better protect the aquatic environment, a detailed analysis of the behavior of marine animals in their natural habitat could be essential. From this necessity, various monitoring approaches have already been proposed to observe the behavior of marines organisms. For example, Mussel Watch [1], which is considered the first step towards a global marine monitoring. These monitoring methods made available a lot of data collected from the field regarding marine animals. Specifically, it opened up a new horizon for a more detailed biological and mathematical analysis of marine animals behavior that was not possible before.

Hafiz Ahmed, Rosane Ushirobira and Denis Efimov are with the NonA team, Inria, Parc Scientifique de la Haute Borne, 40 avenue Halley, 59650 Villeneuve d'Ascq, France, \{hafiz.ahmed, rosane.ushirobira, denis.efimov@inria.fr\}. Damien Tran, Mohamedou Sow and Jean-Charles Massabuau are with Université Bordeaux 1, Centre National de la Recherche Scientifique (CNRS), Unité Mixte de Recherche (UMR) 5805 Environnement et Paléoenvironnement Océanique et Continental (EPOC), Arcachon, France and the EA team at UMR 5805 EPOC-OASU, Bordeaux, France, \{d.tran, m.sow, jc.massabuau@epoc.u-bordeaux1.fr\}. Denis Efimov is also with CRIStAL UMR 9189, Ecole Centrale de Lille, Avenue Paul Langevin, 59651 Villeneuve d'Ascq, France.

Hafiz Ahmed is partially supported by the regional council of Nord-Pas de Calais, France

D. Efimov is with Department of Control Systems and Informatics, Saint Petersburg State University of Information Technologies Mechanics and Optics (ITMO), 49 av. Kronverkskiy, 197101 Saint Petersburg, Russia.

This work was supported in part by the Government of Russian Federation (Grant 074-U01) and the Ministry of Education and Science of Russian Federation (Project 14.Z50.31.0031).
Bivalves, like oysters and mussels, are widespread throughout the world and represent a key element in the ecology and economy of coastal ecosystems. A large scale monitoring of bivalves has been taking place for quite a long time [2]. One such project is "MolluSCAN eye", a remarkable monitoring solution that records the valve activity of bivalves in various geographical location in Europe, Arctic and Tropics ${ }^{1}$. The data obtained from this project makes possible the analysis of behavior of various bivalves from field measurements. These datasets lead to the successful study on various aspects of oysters behavior like the existence of rhythms [3], [4], [5], growth rates [6], behavioral response to harmful algae exposure [7], [8], growth rate recording [9], ecological monitoring [10] and so on.

In this work, we were interested in a particular behavior of oysters, i.e. their behavior during reproduction also known as spawning. Spawning is characterized by rapid and rhythmic contraction and relaxation of the valve to expel eggs in the water. Spawning observation is important in domains like aquaculture, ecology etc. In [10], it was shown that the deviation of valve activity from normal behavior (i.e. slow and non rhythmic contraction and relaxation of valve) can be used as an automatic tool to suspect pollution in surrounding water. Spawning behavior is a deviation from normal behavior but not caused by pollution, so it is necessary to distinguish this particular behavior from any other behavior. The motivation of the current work comes from this necessity. The basis of our work is the valve activity dataset of the MolluSCAN eye project recorded in the Bay of Arcachon, France in 2007.

The goal of this paper is to develop an algorithm that can automatically detect spawning in oysters. In [11], P. S. Galtsoff did this detection by visual inspection under laboratory conditions. Moreover, due to various technical limitations (for example, unavailability of appropriate sensors in 1938), the recording of valve movements were limited in order to measure the data. This type of approach required constant attention, labor and experience to analyze and detect some spawning behavior as it occurs once or twice a year. An increasing number of online measurements for different populations of oysters makes this manual detection approach unpractical due to a big amount of data to be permanently analyzed by an expert. Therefore a solution is an automatic detection of the spawning. In this perspective, spawning can be then considered as a fault [12]. This paper proposes the algorithm to detect that fault.

The outline of the paper is as follows: a brief description of the measurements scheme and experiments is given in section

\footnotetext{
${ }^{1}$ http://molluscan-eye.epoc.u-bordeaux 1.fr/
} 
II (a more detailed information can be found in [13], [14], [15]). The processing of obtained data through section II is discussed in section III. Spawning behaviors of oysters are summarized in section IV while the detection of spawning is discussed in section V. Section VI contains the results and the conclusion of this work can be found in section VII.

\section{Measurement System Description}

The monitoring site is situated in the Bay of Arcachon, France, at the Eyrac pier (Latitude: $44^{\circ} 40 \mathrm{~N}$, Longitude: $1^{\circ} 10$ W). Sixteen Pacific oysters, Crassostrea gigas, measuring from $8 \mathrm{~cm}$ to $10 \mathrm{~cm}$ in length were permanently installed on this site. These oysters were all from the same age group (1.5 years old) and came from the same local supplier. They also all grew in the Bay of Arcachon. They were permanently submerged on the sea bottom (at $3 \mathrm{~m}$ to $7 \mathrm{~m}$ deep in the water, depending on the tide activity).

The basic principles of the measurement process has been first described in [15]. It was further modified later on in [16]. A significant advantage of the developed monitoring system at sea lies in the fact that it is completely autonomous, without in situ human interference for at least one full year. Each animal is equipped with two lightweight coils (sensors), $\approx 100 \mathrm{mg}$ each, attached on the edge of each valve. These coils measure $2.5 \times 2.5 \times 2 \mathrm{~mm}$ and were coated with a resin sealing before attaching them on the valves. One of the coils sends a highfrequency sinusoidal signal, that is received by another coil. Measurements are performed every $0.1 \mathrm{sec}$ successively (with the frequency $10 \mathrm{~Hz}$ ) for one of the sixteen animals. This means that the behavior of a particular oyster is measured every $1.6 \mathrm{sec}$. Every day, 54000 triplets (1 distance, 1 stamped time value, 1 animal number) are collected for each oyster. The strength of the electric field produced between the two coils is proportional to the inverse of distance between the point of measurement and the center of the transmitting coil, which leads to estimation of the distance between coils.

On the shore, a second electronic unit takes care of the data acquisition and transmission. This unit is equipped with a GSM/GPRS modem and uses Linux operating system for driving the first control unit submerged in the water, managing the data storage with a time stamp, accessing the Internet, and transferring the data. The whole process is done by using an original self-developed software module and hardware that run with mobile phone technology. At the end of a working day, the collected data is transmitted to a central workstation server located in the Marine Station at Arcachon, France. The valve activity data is stored in a central database and the public access to this database is available via a website (under some restrictions on the amount of data $)^{2}$. A schematic description of the monitoring system is presented in Fig. 1.

\section{DATA PREPARATION}

To summarize the description given in the previous section, after a specified duration of the experiment, the electronic system provides a matrix of values of opening of valves for each oyster $P_{i, j} \in[0,12 \mathrm{~mm}]$ for $1 \leq i \leq N, \quad 1 \leq j \leq n$, where $n=16$ is the number of oysters in the experiment

\footnotetext{
${ }^{2} \mathrm{http}: / /$ molluscan-eye.epoc.u-bordeaux $1 . \mathrm{fr} /$
}

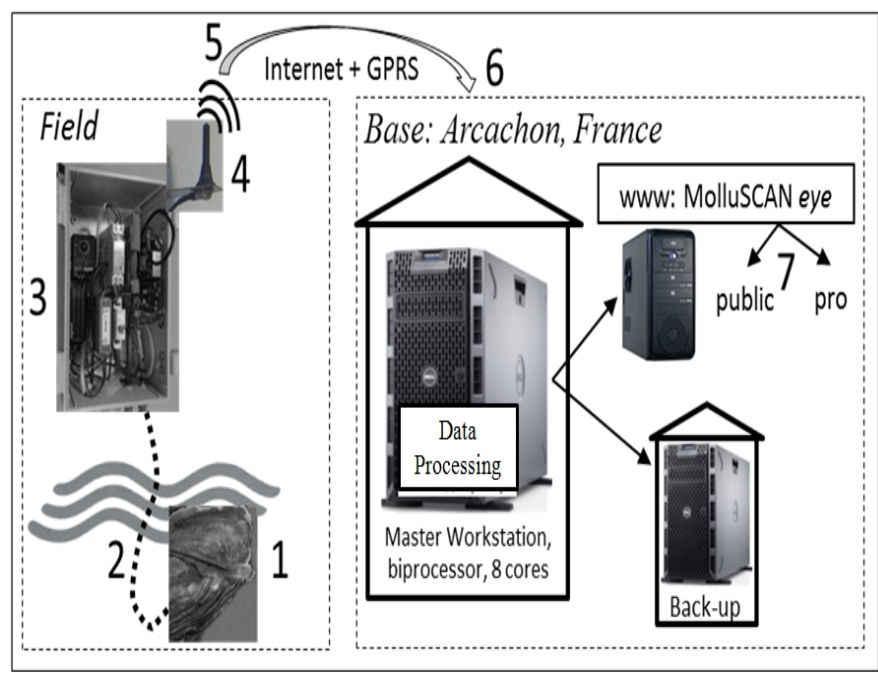

Figure 1. [14] Synoptic representation of the system, from field to laboratory: (1) Sixteen oysters equipped with a couple of electrodes each; cables from oysters to 1st level electronic card; 1st level electronic card in a waterproof box (this whole set is permanently immersed); (2) electrical connection between the first and the second electronic cards; (3) second electronic card (emerged); (4) GPRS antennae; (5) GPRS and Internet connection; (6) Marine Station of Arcachon; (7) daily update on Internet

and $N$ is the number of measured points, $N=54000 \times N_{\text {days }}$ where $N_{\text {days }}>0$ is the number of days of measurement. In our case, the dataset of 2007 collected at the Eyrac pier in the Bay of Arcachon has been used. So, $N_{\text {days }}=365$. For the population, i.e. for 16 oysters, the measurement system gave us total 315.36 million data points. The valve opening activity of three different oysters is illustrated in Fig. 2 where we can see that the valve distance activity is not uniform among the oysters. For example, for oyster $\mathrm{N}^{\circ} 7$ the valve distance is moving around $2-6 \mathrm{~mm}$ most of the time while for oyster $\mathrm{N}^{\circ} 12$, it varies between $5-10 \mathrm{~mm}$. This diversity is originated by the difference of shell anatomy between animals and variable placement of sensors on valves. To compensate for this variability we normalized the data between certain bounds. Here, the normalization was done considering a 6 days window and with a bound $[0,1]$, where 0 represents complete closing of the valve while 1 represents complete opening of the valve. The formula to calculate the normalized value is:

$$
p_{i, j}=\frac{P_{i, j}-\min \left(P_{k, j}\right)}{\max \left(P_{k, j}\right)-\min \left(P_{k, j}\right)}
$$

where $k=i-N_{t}, \cdots, i$ with $N_{t}$ the total number of data points in last 6 days, $P_{i, j}$ is the actual valve distance and $p_{i, j}$ is the normalized valve distance. For further work, we have considered this normalized/scaled data instead of the original one [10].

\section{SPAWNING OF OYSTERS}

For oysters, the experimental study of spawning dates back to 1938, when American biologist Paul S. Galtsoff published his seminal work on the physiology of reproduction of oysters [11]. Based upon laboratory observation, spawning is a specific/particular type of shell/valve activity of female oysters [17], [18]. In [11], an ostreograph was used to measure 


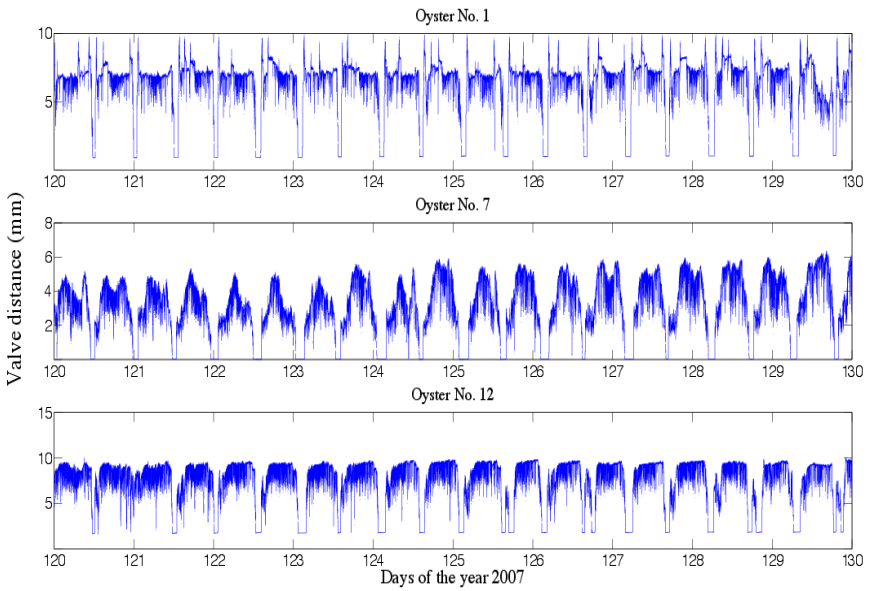

Figure 2. Actual valve distance of three different oysters during 10 days

the valve activity and that data was later used to study spawning. Under normal environmental conditions shell/valve movements are characterized by long relaxation periods which may vary from a few minutes to hours and are often interrupted by secondary contractions. While during spawning (see Fig. 3 , oyster 1 and 3 ), it can be seen that a series of rapid contractions and relaxations are occurring following one after another with remarkable regularity and continuing for about $30-40$ minutes. Consistency in the amplitude of the relaxation curve, especially during the first half of the reaction and the remarkable rhythmicity of the contractions are the most distinctive features of the sexual reaction of a female. This phenomenon doesn't occur under any other circumstance. Burst of valve activity can be seen in other cases as well like under the influence of some external excitation (for example pollution or chemical injection) but (1) their frequency is never so regular, (2) will last for shorter period of time and (3) will have long relaxation period. It was also known that spawning propagates from one to another and eventually over a large fraction of the oyster community [11].

So, any rhythmic behavior to be considered as spawning should have certain characteristics. They are, for example, regularity in rhythm, consistency in amplitude, happening for $30-40$ minutes, short relaxation period, synchronization of spawning in the population, etc. However, spawning can happen with mild characteristics also (see Fig. 3, oysters 7 and 15). For example, instead of $30-40$ minutes duration, it can last $10-20$ minutes. In this work, we will focus on detecting any spawning behavior with strong characteristics or clearly distinguishable. So, the spawning behavior can be considered as a deviation from normal behavior. In Fault Detection literature, this is known as fault (i.e. deviation from normal behavior). Hence, the detection of this fault is equivalent to the detection of spawning.

In our experiment, we have collected the data of 16 oysters. From that dataset, we also found similar behavior as reported in [11]. In our case, the oysters happened to spawn on the 15th July, 2007. The data of 4 oysters including both spawning and non-spawning oysters can be seen in Fig. 3. A close look on oysters $\mathrm{N}^{\circ} 3$ and $\mathrm{N}^{\circ} 15$, can be seen in Fig. 4. In this figure,
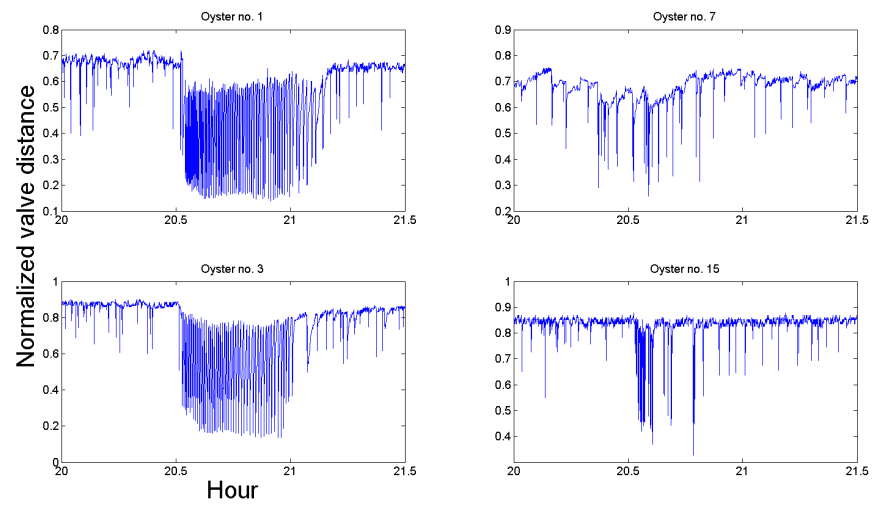

Figure 3. Spawning and non-spawning behavior of oysters

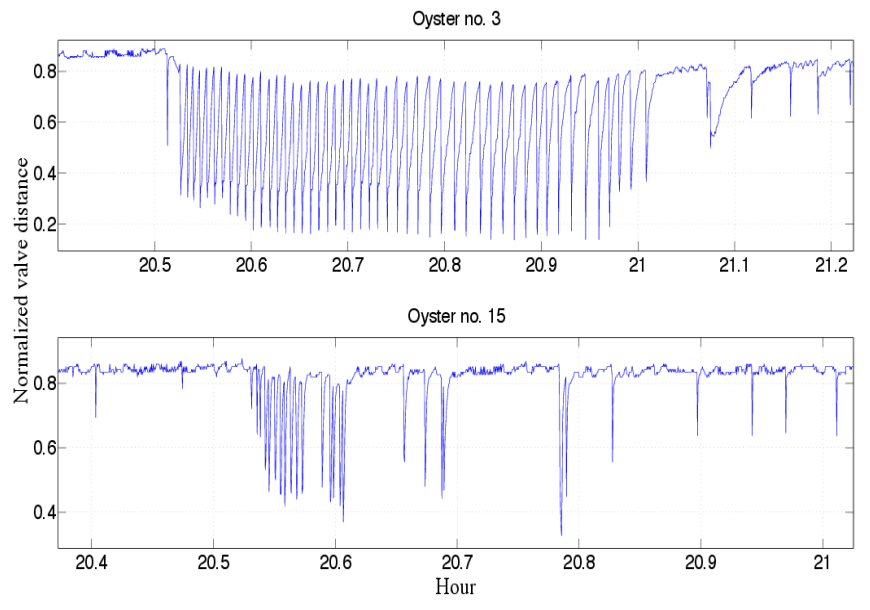

Figure 4. Behavior of oyster $\mathrm{N}^{\circ} 3$ and 15 (zoomed)

we can clearly see that oyster $\mathrm{N}^{\circ} 3$ fulfills all the criteria to call its rhythmic behavior as female spawning according to [11] (regular rhythmicity, consistency in the amplitude during rhythmic behavior, happening for about $30-40$ minutes, contraction followed by relaxation or vice-versa with short relaxation period, etc.). However, if we look at oyster $\mathrm{N}^{\circ} 15$, it is evident from its behavior that it is not spawning with distinguishable characteristics (like $30-40$ minutes duration, very regular contraction and relaxation, etc.) although some rhythmicity can be seen. So, oyster $\mathrm{N}^{\circ} 15$ is not showing the type of spawning that we are interested in detecting in this work. Similarly, we can say that oyster $\mathrm{N}^{\circ} 1$ is spawning and $\mathrm{N}^{\circ} 7$ is not spawning in Fig. 3.

\section{Automatic Detection of Spawning}

Detection of spawning is totally done by visual analysis until now. In one of our previous works, we have tried to establish a relation between water quality and abnormal valve activity [10]. There, we have showed that the deviation of valve activity from normal behavior, if it occurs in the whole animal group, can be used as an indicator for change in water quality. Since spawning behavior is a total deviation from normal behavior, according to [10], it could also be considered as an indicator for change in water quality. However, in reality this is a totally normal behavior having little to do with the occurrence of poor water quality. So, by automatic spawning 
detection, we will be able to differentiate spawning behavior from numerous other abnormal motion. Moreover, it will save time and labor of visually analyzing the data to find the period of spawning. So, automatic detection of spawning can be useful in the above mentioned cases.

A typical pattern of spawning behavior (see Fig. 3) is a series of contraction and relaxation of valves. In other words, the velocity of valve movement is fluctuating in a regular rhythmic manner. Since the kinetic energy is related to the velocity, it will also fluctuate very rapidly and regularly. By passing this high frequency kinetic energy like a signal through a specially designed low-pass filter, we can expect to extract some features related to spawning. They can then be used for the detection of spawning.

The main idea of our spawning detection algorithm is first to calculate the velocity of valve movement. Velocity is nothing but the time derivative of the measured distance. Once we estimate the velocity, this information can be used to calculate the energy (square of velocity). Then by passing this energy through a low-pass filter and comparing the value with some pre-defined threshold, we can detect spawning which is a typical approach used for fault detection [12]. We have chosen energy signal as the marker because it is easier to obtain a pattern from the square of a velocity signal (having higher amplitude during spawning) than the velocity itself because of the amplitude. The details of the spawning detection algorithm are given below.

\section{A. Velocity Estimation}

Since velocity is the time derivative of valve distance activity, we need to differentiate the valve distance to get the velocity. There exist various effective methods like [19], [20], [21]. Out of various methods available, we have chosen the technique proposed in [19] based on algebraic method because of its simplicity, effectiveness and noise compensation. A more detailed description of the approach can be found in [19], [22]. According to this method for a real-valued signal $y(t)$, analytic on some time interval, the first-order time derivative estimate for discrete time case can be written as:

$$
\hat{\dot{y}}_{k}=\frac{6}{M^{2} T_{s}} \sum_{l=0}^{M}\left(1-2 \frac{l}{M}\right) y_{k-l}
$$

where $t_{k-l}=(k-l) T_{s}, y_{k-l}=y\left(t_{k-l}\right), T_{s}$ is the sampling time and $M$ is the number of summation steps i.e. $T=M T_{s}$.

\section{B. Filtering of energy signal and spawning detection}

From the normalized valve distance data $p_{i, j}$, using equation (1) we can easily estimate the velocity $v_{i, j}$. From the estimated velocity, the kinetic energy like signal can be calculated by taking square of the velocity signal as:

$$
E_{i, j}=v_{i, j}^{2}
$$

where $E_{i, j}$ is the energy and $v_{i, j}$ is the velocity. This signal will be passed through the following low-pass like filter:

$$
f_{i+1, j}=f_{i, j}+T_{s}\left(\min \left(\gamma,\left|E_{i, j}\right|\right)-\mu f_{i, j}\right)
$$

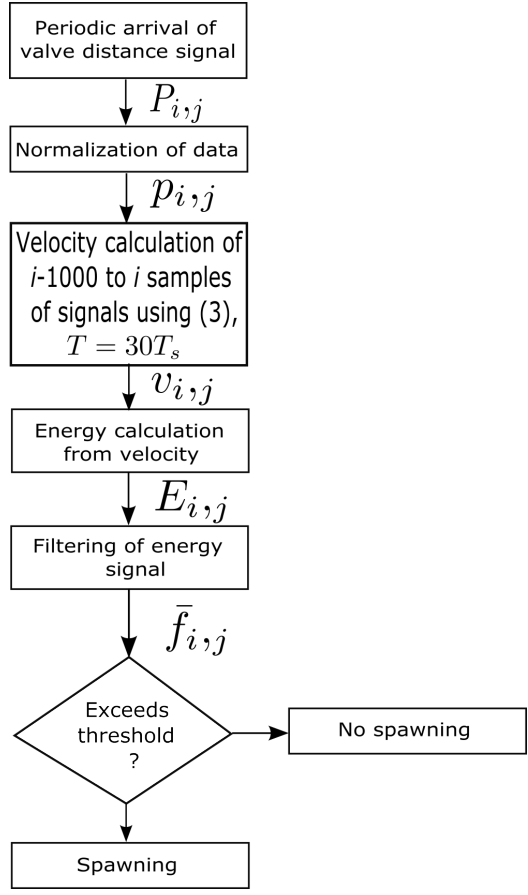

Figure 5. Flow chart of spawning detection process

where $f_{i, j}$ is the filtered signal, $T s=1.6 \mathrm{sec}$. is the sampling period and $\mu, \gamma$ are the parameters of the filters. The filtered signal obtained through (2) will then be passed through another typical low-pass filter to eliminate the remaining high frequency fluctuation of the energy signal to differentiate the spawning and non spawning case. In some cases, the pattern of spawning and non-spawning signals are very similar (Oyster 8 and 12 in Fig. 8). Double low-pass filtering helps to differentiate in that case. The transfer function of a typical first order low pass filter has the following form:

$$
H(s)=\frac{1}{1+\frac{s}{\omega_{c}}}
$$

where $\omega_{c}$ is the cut-off frequency of the filter. This doubly filtered energy signal will then be used for the detection of the spawning. If the signal exceeds some threshold, it will be considered as spawning otherwise no spawning:

$$
\text { Spawning }= \begin{cases}1, & \bar{f}_{i, j} \geq \beta \\ 0, & \text { otherwise }\end{cases}
$$

where $\bar{f}_{i, j}$ is the doubly filtered energy signal and $\beta$ is the threshold for spawning.

The flowchart of the process can be seen in Fig. 5. The parameters of the algorithm were tuned on a trial and error basis since establishing some tuning is very difficult because of the wide variations of behavior among different animals. The values of the parameters are omitted for space limitations.

\section{RESUlts AND Discussions}

As mentioned in Section IV, the spawning oysters can be identified by visual inspection of the data. After such an expert evaluation, the oysters $\mathrm{N}^{\circ} 1,3,4,10,11,12,13$ and 16 were classified as clearly visible spawning oysters with spawning 
period of about $30-40$ minutes and having very regular rhythmic contraction and relaxation of valves. By this we will find the spawning oysters. Next the proposed algorithm has been applied. For example, the data of oysters $\mathrm{N}^{\circ} 1$ and 5 can be seen in Fig. 6. According to the criteria mentioned in section IV, oyster $\mathrm{N}^{\circ} 1$ is classified as a typical spawner while $\mathrm{N}^{\circ} 5$ appears to exhibit a much lesser typical burst of contraction. Note that to be certain that 5 was really spawning or not would require the ability to check if it produces eggs or not, which was clearly out of the scope of the present work. The final output of our algorithm in this case can be seen in Fig. 7. From Fig. 6, it is clear that our algorithm can successfully detect the start and end of spawning. The result for the total population can be seen in Fig. 8. From Fig. 8, we can see that our algorithm can detect the spawning for all the clear cut spawning oysters. There is no false alarm and zero misdetection. This proves the effectiveness of our algorithm. However, in some cases we can see a little delayed detection. The delay appears from filtering and threshold selection mainly which is intentional to eliminate the chance of false detection. From Fig. 8, some abnormal contractions in the male populations can be seen also which is very similar to spawning. It can be said in this case that the male oysters are showing some kind of reaction to their female counterpart.

As mentioned in Section IV, according to [11], spawning propagates from one to another and then induces an increased burst activity that eventually spread to most individuals. This is a very important criteria to check if the oysters are really spawning, which may tolerate the effect of wrong detection of the algorithm for certain oysters. If they are really spawning, we would see the spawning propagating, otherwise not. One way to check this criteria is to calculate the number of oysters synchronously spawning at a given time. The number of synchronously spawning oysters in our case can be seen in Fig. 9 where we remark that the spawning spread from one oyster to another and then eventually spread to the entire community. At the peak of spawning, all female oysters were spawning. This is a very strong proof of spawning and also tells the effectiveness of our spawning detection algorithm. Moreover, we can see that it took very short time (approximately 7 minutes in this particular case) to propagate spawning from the first spawning oyster to the second one and much less for the rest of the oysters.

\section{CONCLUSIONS}

This paper presents an algorithm to automatically detect the start and end of the spawning period of a population of oysters, that is, to detect individual spawning events and the day of spawning. The developed algorithm is based on the estimation of velocity of valve movement. The algorithm was then tested on a population to validate its effectiveness. The obtained results are very promising and open up the scope of real-time spawning detection of oyster population in marine environment.

In future works, the algorithm can be tested on new measurement sites and different bivalves species. This work considered only strongly distinguishable spawning cases. Less evident cases should also be detected in future works. Moreover, delay improvement can also be done since there exists
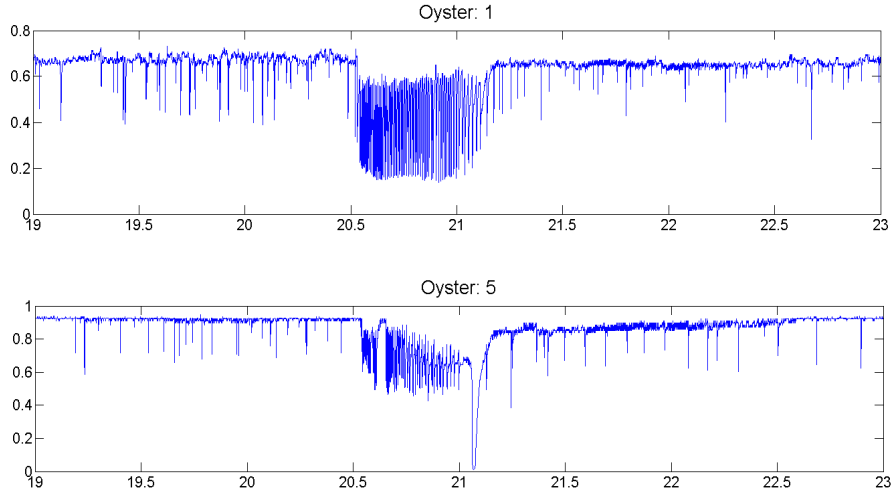

Figure 6. Valve activity of oyster 1 and 5 (x-axis is in hour and y-axis is normalized valve distance)
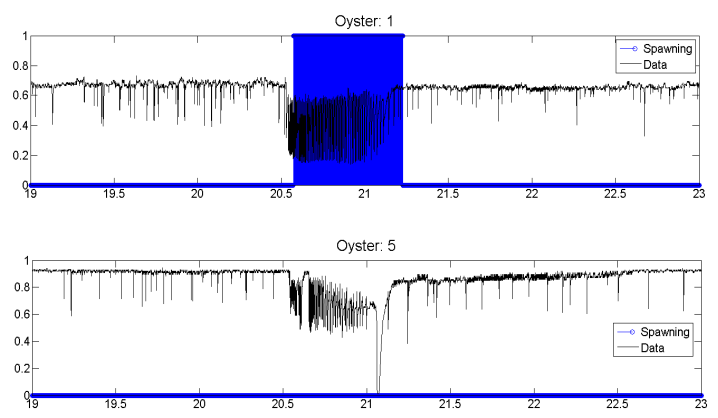

Figure 7. Result of the spawning detection algorithm for oyster 1 and 5 (Blue signal indicates spawning)

a gap in the detection for some oysters. Very noisy/faulty measurement detection system can also be included into the algorithm to prevent any false/early/late detection. Once a spawning day has been automatically identified, it is thus a solid working base for an expert to screen the records and classify the atypical bursts of contractions.

\section{REFERENCES}

[1] E. D. Goldberg, "The mussel watch-a first step in global marine monitoring," Marine Pollution Bulletin, vol. 6, no. 7, p. 111, 1975.

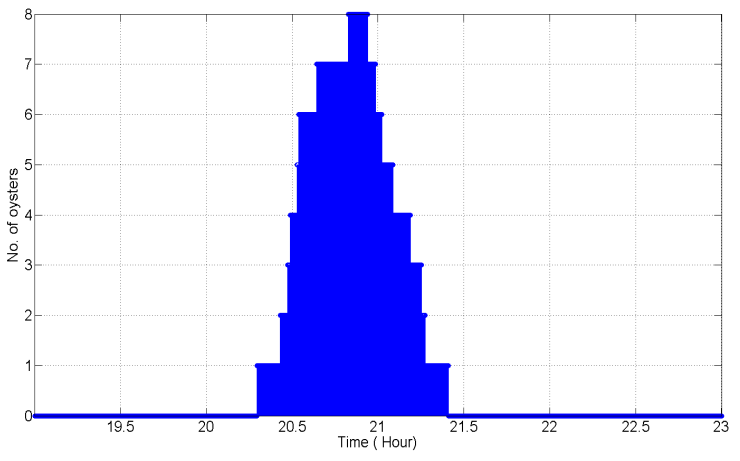

Figure 9. Number of synchronously spawning oysters 

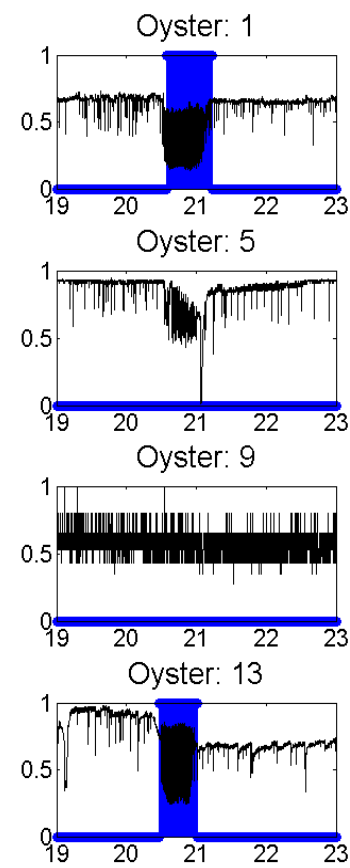

Spawning Detection Dashboard

Oyster: 2

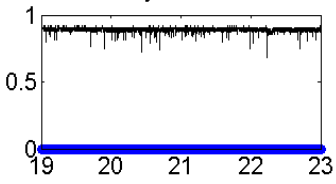

Oyster: 6

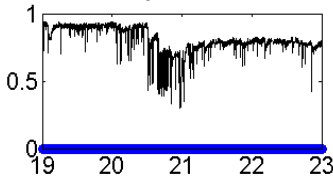

Oyster: 10
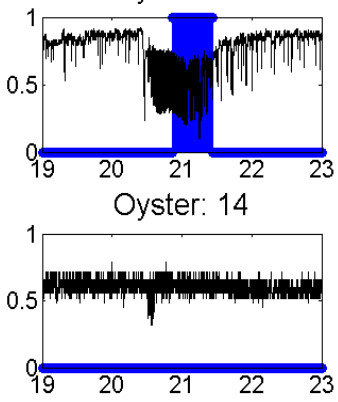

Oyster: 3
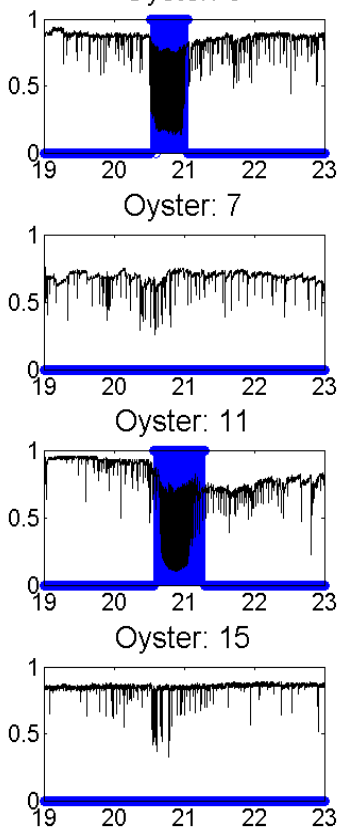
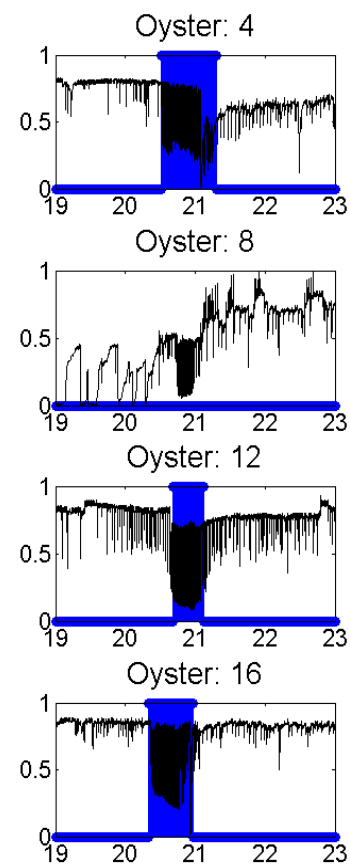

Figure 8. Spawning detection for the population

[2] P. Scanes, "Oyster watch: Monitoring trace metal and organochlorine concentrations in sydney's coastal waters," Marine Pollution Bulletin, vol. 33, no. 7, pp. 226-238, 1996.

[3] A. M. Mat, J.-C. Massabuau, P. Ciret, and D. Tran, "Evidence for a plastic dual circadian rhythm in the oyster crassostrea gigas," Chronobiology international, vol. 29, no. 7, pp. 857-867, 2012.

[4] A. M. Mat, J.-C. Massabuau, P. Ciret, and D. Tran, "Looking for the clock mechanism responsible for circatidal behavior in the oyster crassostrea gigas," Marine Biology, vol. 161, no. 1, pp. 89-99, 2014.

[5] D. Tran, A. Nadau, G. Durrieu, P. Ciret, J.-P. Parisot, and J.-C. Massabuau, "Field chronobiology of a molluscan bivalve: How the moon and sun cycles interact to drive oyster activity rhythms," Chronobiology international, vol. 28, no. 4, pp. 307-317, 2011.

[6] C. Schwartzmann, G. Durrieu, M. Sow, P. Ciret, C. E. Lazareth, and J.-C. Massabuau, "In situ giant clam growth rate behavior in relation to temperature: A one-year coupled study of high-frequency noninvasive valvometry and sclerochronology," Limnology and oceanography, vol. 56, no. 5, pp. 1940-1951, 2011.

[7] D. Tran, H. Haberkorn, P. Soudant, P. Ciret, and J.-C. Massabuau, "Behavioral responses of crassostrea gigas exposed to the harmful algae alexandrium minutum," Aquaculture, vol. 298, no. 3, pp. 338-345, 2010.

[8] A. M. Mat, H. Haberkorn, J.-P. Bourdineaud, J.-C. Massabuau, and D. Tran, "Genetic and genotoxic impacts in the oyster crassostrea gigas exposed to the harmful alga alexandrium minutum," Aquatic Toxicology, vol. 140 , pp. $458-465,2013$.

[9] D. Tran, J.-C. Massabuau, and C. Vercelli, "Influence of sex and spawning status on oxygen consumption and blood oxygenation status in oysters crassostrea gigas cultured in a mediterranean lagoon (thau, france)," Aquaculture, vol. 277, no. 1, pp. 58-65, 2008.

[10] H. Ahmed, R. Ushirobira, D. Efimov, D. Tran, J.-C. Massabuau, et al., "Dynamical model identification of population of oysters for water quality monitoring," in Proc. European Control Conference (ECC) 2014, 2014.

[11] P. S. Galtsoff, "Physiology of reproduction of ostrea virginica i. spawning reactions of the female and male," The Biological Bulletin, vol. 74, no. 3 , pp. $461-486,1938$.

[12] A. Zolghadri, D. Henry, J. Cieslak, D. Efimov, and P. Goupil, Fault Diagnosis and Fault-Tolerant Control and Guidance for Aerospace Vehicles: From theory to application. Advances in Industrial Control, Springer London Ltd, Oct. 2013.
[13] M. Sow, G. Durrieu, L. Briollais, P. Ciret, and J.-C. Massabuau, "Water quality assessment by means of hfni valvometry and high-frequency data modeling," Environmental monitoring and assessment, vol. 182, no. 1-4, pp. $155-170,2011$.

[14] F. G. Schmitt, M. De Rosa, G. Durrieu, M. Sow, P. Ciret, D. Tran, and J.C. Massabuau, "Statistical study of bivalve high frequency microclosing behavior: Scaling properties and shot noise analysis," International Journal of Bifurcation and Chaos, vol. 21, no. 12, pp. 3565-3576, 2011.

[15] D. Tran, P. Ciret, A. Ciutat, G. Durrieu, and J.-C. Massabuau, "Estimation of potential and limits of bivalve closure response to detect contaminants: application to cadmium," Environmental Toxicology and Chemistry, vol. 22, no. 4, pp. 914-920, 2003.

[16] C. Chambon, A. Legeay, G. Durrieu, P. Gonzalez, P. Ciret, and J. Massabuau, "Influence of the parasite worm polydora sp. on the behaviour of the oyster crassostrea gigas: A study of the respiratory impact and associated oxidative stress," Mar. Biol., vol. 152, pp. 329-338, 2007.

[17] E. His, Contribution à l'étude biologique de l'huitre dans le bassin d'Arcachon. Activité valvaire de Crassostrea angulata et de Crasssotrea gigas ; application à la reproduction de l'huitre japonaise. $\mathrm{PhD}$ thesis, University of Bordeaux 1, 1976.

[18] I. Bernard, Ecologie de la reproduction de l'huitre creuse, Crassostrea gigas, sur les cotes atlantiques francaises: vers une explication de la variabilite du captage. $\mathrm{PhD}$ thesis, University of La Rochelle, 2011.

[19] M. Mboup, C. Join, and M. Fliess, "Numerical differentiation with annihilators in noisy environment," Numerical Algorithms, vol. 50, no. 4 pp. 439-467, 2009.

[20] W. Perruquetti, T. Floquet, and E. Moulay, "Finite-time observers: application to secure communication," Automatic Control, IEEE Transactions on, vol. 53, no. 1 , pp. 356-360, 2008.

[21] D. Efimov and L. Fridman, "A hybrid robust non-homogeneous finitetime differentiator," Automatic Control, IEEE Transactions on, vol. 56, no. 5, pp. 1213-1219, 2011.

[22] R. Ushirobira, W. Perruquetti, M. Mboup, and M. Fliess, "Algebraic parameter estimation of a multi-sinusoidal waveform signal from noisy data," in Control Conference (ECC), 2013 European, pp. 1902-1907, IEEE, 2013 